\title{
Humboldt penguins monitored via VHF telemetry
}

\author{
Boris M. Culik ${ }^{1, *}$, Guillermo Luna-Jorquera ${ }^{2}$, Hector Oyarzo ${ }^{3}$, Hector Correa ${ }^{3}$ \\ ${ }^{1}$ Institut für Meereskunde, Düsternbrooker Weg 20, D-24105 Kiel, Germany \\ ${ }^{2}$ Universidad José Santos Ossa, Los Inmigrantes 733, Casilla 1344, Antofagasta, Chile \\ ${ }^{3}$ Corporación Nacional Forestal, Dirección Región de Atacama, Atacama 898, Copiapó, Chile
}

\begin{abstract}
VHF telemetry was used in November and December 1995 on 8 Humboldt penguins Spheniscus humboldti breeding at Pan de Azúcar Island $\left(26^{\circ} \mathrm{S}, 70^{\circ} \mathrm{W}\right)$, Northern Chile, to determine atsea behaviour of the birds. We obtained 2710 locations, $90 \%$ of which were within a radius of $20 \mathrm{~km}$ around the island. Mean travelling speed of the birds was $0.92 \mathrm{~m} \mathrm{~s}^{-1}$ and speed distribution showed peaks at 1.6 and $3 \mathrm{~m} \mathrm{~s}^{-1}$ Penguins travelling between foraging areas remained submerged for an average of $8.4 \mathrm{~s}$ between surfacings, whereas foraging dives lasted on average $61 \mathrm{~s}$. The analysis of $79 \mathrm{com}-$ plete foraging trips showed that tracks deviated from a straight course, and range (maximum distance from island) was only 0.37 times total horizontal distance swum. Birds did not forage synchronously or in the same foraging areas. However, foraging ranges were correlated between birds, indicating similar search strategies during periods of low food availability. The results obtained here via VHF telemetry agreed well with those of previous studies employing satellite transmitters and data loggers.
\end{abstract}

KEY WORDS: Behaviour Diving · Foraging

\section{INTRODUCTION}

The Humboldt penguin Spheniscus humboldti is endemic to the area influenced by the cold, nutrientrich Humboldt current, and breeds on the mainland coast and offshore islands of Perú and Chile, from $5^{\circ} \mathrm{S}$ to about $42^{\circ} \mathrm{S}$ (Williams 1995). The population declined severely during the El Niño of 1982-83 and latest population estimates range in the order of only 13000 birds (CAMP 1996). However, a recent census in Chile has indicated a further decline in February 1997 (H. O. Yarzo unpubl. data), which may be related to commercial fisheries, unfavourable oceanographic conditions, or both.

In a previous paper (Culik \& Luna-Jorquera 1997), we were able to show that deteriorating oceanographic conditions (i.e. depression of the thermocline and reduced nutrient availability) indicated by positive sea surface temperature anomalies (SSTA) are paralleled by a decrease in fishery landings, and that reduced prey availability is probably the cause for increased

-E-mail: bculik@ifm.uni-kiel.de daily dive durations of Humboldt penguins during the same period.

In order to determine how Humboldt penguins utilise their marine habitat, we previously used ARGOS satellite transmitters (Culik \& Luna-Jorquera 1997). However, these only provided 2-dimensional spatial resolution and an average of 2.7 locations $\mathrm{d}^{-1}$. We also used time-depth-velocity recorders (LunaJorquera \& Culik 1997), but these did not provide spatial resolution and recorded data at $5 \mathrm{~s}$ intervals. In the present study, we report on results obtained using small VHF transmitters, which provided us with high spatial and temporal resolution. Our aims in this study were to determine (1) activity patterns, (2) small-scale feeding areas used by the birds at sea, (3) dive duration, (4) travelling speed and (5) how our results compare to and complement those obtained through the other 2 methods.

\section{MATERIALS AND METHODS}

This study was conducted on Pan de Azúcar Island in Pan de Azúcar National Park $\left(26^{\circ} \mathrm{S}, 70^{\circ} \mathrm{W}\right)$, Northern 
Chile, from November 5 to December 31, 1995, following the guidelines of the Corporación Nacional Forestal, Copiapó, Chile. Eight Humboldt penguins (mean mass $4.35 \pm 0.35 \mathrm{~kg}$ ) were injected at their nest site with $0.25 \mathrm{ml}$ ketamine hydrochloride (Ketavet, ParkeDavis GmbH, Berlin, Germany) and their heads covered, to minimise stress while being handled (LunaJorquera et al. 1997). Subsequently, the birds were equipped with streamlined (Bannasch et al. 1994) Telonics (Mesa, AZ, USA) MOD 225 transmitters $193 \mathrm{~g}$, $80 \times 32 \times 18 \mathrm{~mm}$ ) by attaching the devices to the feathers on the back, below the line of maximal girth, using adhesive tape (TESA-Beiersdorf, Hamburg, Germany) according to Wilson \& Wilson (1989). The whole attachment procedure lasted approx. 10 min per penguin. Transmitters emitted 1 pulse every $0.45 \mathrm{~s}$ through a $30 \mathrm{~cm}$ long, vertical antenna which was designed to break the sea surface immediately upon surfacing of the penguin.

Penguins 1 to 5 were equipped between November 5 and 8 and birds 6 to 8 on November 15. All penguins were either on eggs just prior to hatching or tending small chicks ( $<125 \mathrm{~g}$ ) but 1 bird (no. 8) was tending large chicks (500 and $1200 \mathrm{~g}$, respectively). Three days after being equipped, penguins no. 5 and 7 abandoned their nest and were followed $2 \mathrm{~d}$ later by nos. 1, 3, 4 and 7. Only birds no. 2 and 8 continued breeding after November 19. Because the reasons for breeding failure were unclear - failure could have been due to handling or just human presence in the area - we did not continue nest checks thereafter. The overall impact of our investigation on Pan de Azúcar's Humboldt penguin population could not be assessed, because comparison (e.g. adult and chick mass, regular checks of breeding success) of equipped and non-equipped birds was judged to lead to undue additional stress to a species which is very difficult to investigate and because, besides the birds we equipped, there were very few active nests in the area. Transmitters were presumably removed by the birds during moult in February 1996.

Two pairs of directional receiving antennas (RA-NS 5, Telonics) in an array configuration (null peak) were attached to two $3 \mathrm{~m}$ high, revolving masts. Signals were passed to a ULNPA 150 pre-amplifier (Reimesch, Kürten-Biesfeld, Germany) connected to a Yaesu FT290 RII receiver (Yaesu Musen Co Ltd, Tokyo, Japan) which was powered by a solar cell. One antenna array was placed $4 \mathrm{~km}$ to the northeast of the breeding island on the mainland, at $350 \mathrm{~m}$ elevation above sea level, while the other array was approx. $3 \mathrm{~km}$ to the southeast at $230 \mathrm{~m}$ above sea level. Assuming straight-line signal propagation, we estimated the maximum range to be $50 \mathrm{~km}$.

The distance between antennas was $6.2 \mathrm{~km}$ and the orientation of the base line linking the two was parallel
Table 1. Maximum locational error $( \pm \mathrm{km})$, i.e. length of the long side of the error polygon for 2 antenna arrays (null peak), $6.5 \mathrm{~km}$ apart, with $\mathrm{a} \pm 1^{\circ}$ bearing error for each antenna

\begin{tabular}{|cll|}
\hline Range $(\mathrm{km})$ & \multicolumn{2}{l|}{$\begin{array}{l}\text { Angle relative to base line } \\
90^{\circ}\end{array}$} \\
& $90^{\circ}$ \\
\hline 10 & 0.6 & 0.9 \\
20 & 2.0 & 2.9 \\
30 & 3.8 & 6 \\
\hline
\end{tabular}

to the coast $\left(17^{\circ}\right.$ with respect to north). Antenna bearings were recorded to the nearest degree. Precision of locations was checked every $30 \mathrm{~min}$ with respect to those birds which had remained on the nest site. By comparison with the nest site's true position, we obtained a $\pm 1^{\circ}$ error for bearings, which we used to graphically estimate the size of the error polygon. Table 1 gives the maximum values for the respective polygons, perpendicular to the base line (almost westnorth-west or $287^{\circ}$ ) and at compass bearings $30^{\circ}$ relative to the base line (i.e. $227^{\circ}$ or SW and $347^{\circ}$ or $\mathrm{N}$ NNW). These bearings cover most of the locations obtained (cf. Fig. 1). For a detailed description of location errors encountered in VHF telemetry see Zimmermann \& Powell (1995).

Antenna arrays were manned for ca $8 \mathrm{~h} \mathrm{~d}^{-1}$ (ca 09:00 to $16: 00 \mathrm{~h}$ ) by ourselves and 5 CONAF personnel after conducting a 2 wk workshop to ensure high data quality. Teams on both antennas were in constant VHF radio contact in order to compare bearings and check for errors. All birds were scanned in 30 min intervals. Positions of the birds were obtained by analysing directional data using specially designed software (Jensen Software, Laboe, Germany).

Radio-tag transmission was interrupted whenever the birds were diving. The duration of these periods as well as surfacings were timed to the nearest $0.1 \mathrm{~s}$ using a field computer (Husky Hunter, Coventry, England), after checking through preliminary tests that both receivers detected such pauses simultaneously. For that purpose, antennas were rotated out of the nullpeak bearing by approx. $15^{\circ}$ to give full signal strength. Standard deviations are given after the \pm sign.

\section{RESULTS}

\section{Distribution of birds at sea}

In total we obtained 2710 positions of the birds at sea over a period of $54 \mathrm{~d}$. From these, we were able to reconstruct 79 complete tracks (i.e. birds leaving and returning to the island within the same observation. 

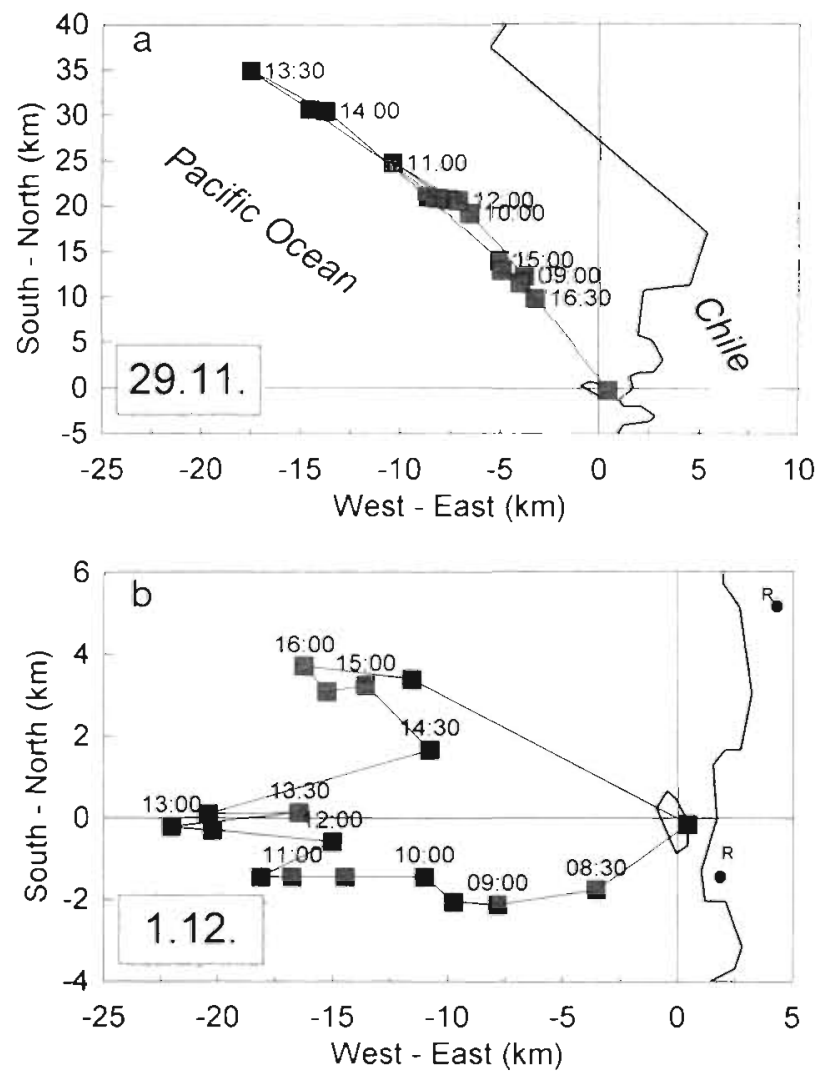

Fig. 1. Spheniscus humboldti. Different types of foraging tracks in Humboldt penguins: (a) linear and (b) covering a large area. The Chilean coast is located to the right of the ongin, which marks the center of the breeding island. Note the difference in scales. (b) $R$ : location of receiving antennas

period) for 6 of the birds. These ranged in shape between 2 categories: either straight to the foraging areas and back to the island (Fig. 1a) or taking a more meandering round trip (Fig. 1b). Distance swum by the birds averaged $44.5 \pm 35 \mathrm{~km}$ ( $\mathrm{n}=79$ foraging tracks).

In order to determine how far birds foraged from the island, we looked at the frequency distribution of their range (distance between breeding island and location at sea; Fig. 2). We found that $90 \%$ of all locations were obtained within a radius of $20 \mathrm{~km}$ around the breeding island $(75 \%$ within $5 \mathrm{~km}, 98 \%$ of locations within $35 \mathrm{~km}$ ).

\section{Travelling speed}

Information on bird position and time allowed us to calculate the mean horizontal travelling speed (which should not be confused with swimming speed) of Humboldt penguins between each 2 locations. For this purpose, however, all individual speeds $<0.1 \mathrm{~m} \mathrm{~s}^{-1}$ or $>6 \mathrm{~m}$ $\mathrm{s}^{-1}$ were excluded from the analysis, because they

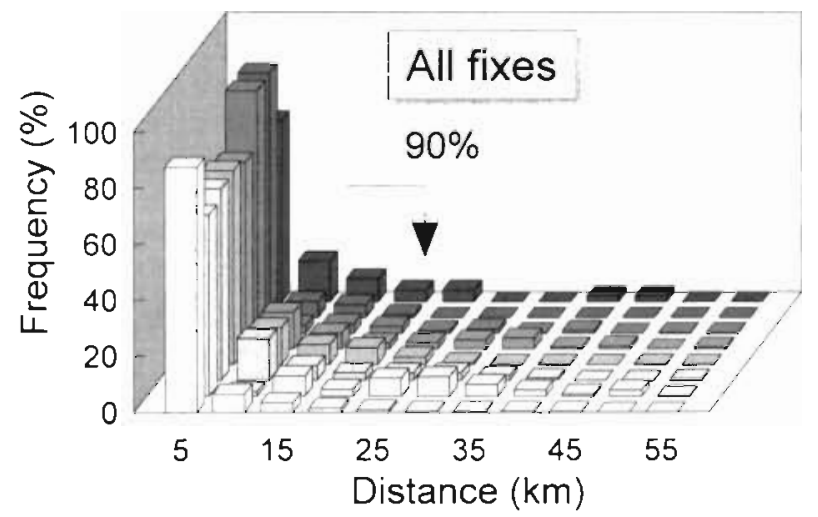

Fig. 2. Spheniscus humboldti. Frequency distribution of location range in 8 Humboldt penguins. $75 \%$ of all locations were within a $5 \mathrm{~km}$ radius of the island, $90 \%$ were within $20 \mathrm{~km}$ and $98 \%$ were within $35 \mathrm{~km}$

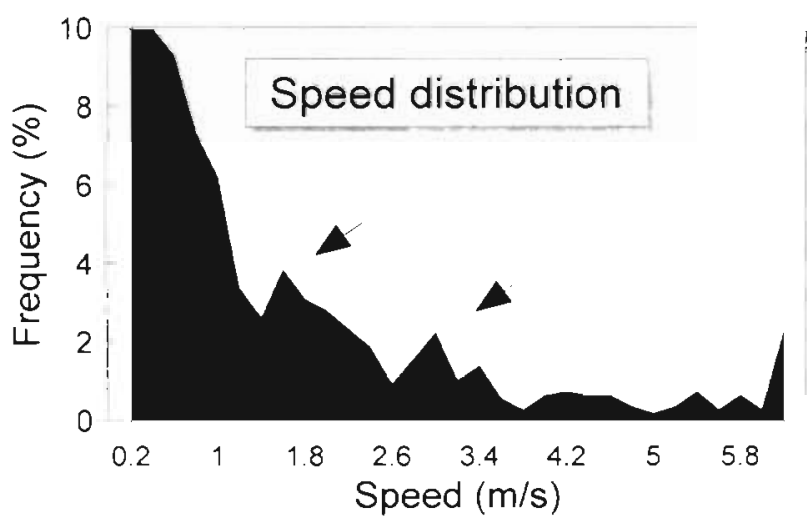

Fig. 3. Spheniscus humboldti. Travelling speed distribution of birds located twice within $30 \mathrm{~min}(\mathrm{n}=150)$. Preferred speeds are indicated by arrows (modes)

were judged to reflect either resting values or values significantly larger than previously reported for swimming penguins (e.g. Wilson 1995), which we attributed to inaccurate location. Mean travelling speed was $0.92 \pm 0.92 \mathrm{~m} \mathrm{~s}^{-1}(\mathrm{n}=150)$. Speed distribution at sea (0.2 $\mathrm{m} \mathrm{s}^{-1}$ speed classes), however, was not uniform and showed 2 distinct peaks, at $1.6 \mathrm{~m} \mathrm{~s}^{-1}(3.9 \%$ of all observations) and at $3 \mathrm{~m} \mathrm{~s}^{-1}$ (2.3\% of observations) (Fig. 3).

\section{Dive durations}

Dive times were timed from periods of uninterrupted transmission pauses and were not normally distributed (Fig. 4a), the distribution showing a minimum at $35 \mathrm{~s}$ and modes at 5 and $55 \mathrm{~s}$, and were therefore separated into 2 categories: short travelling dives between foraging areas $(<35$ s) and long foraging dives when the 

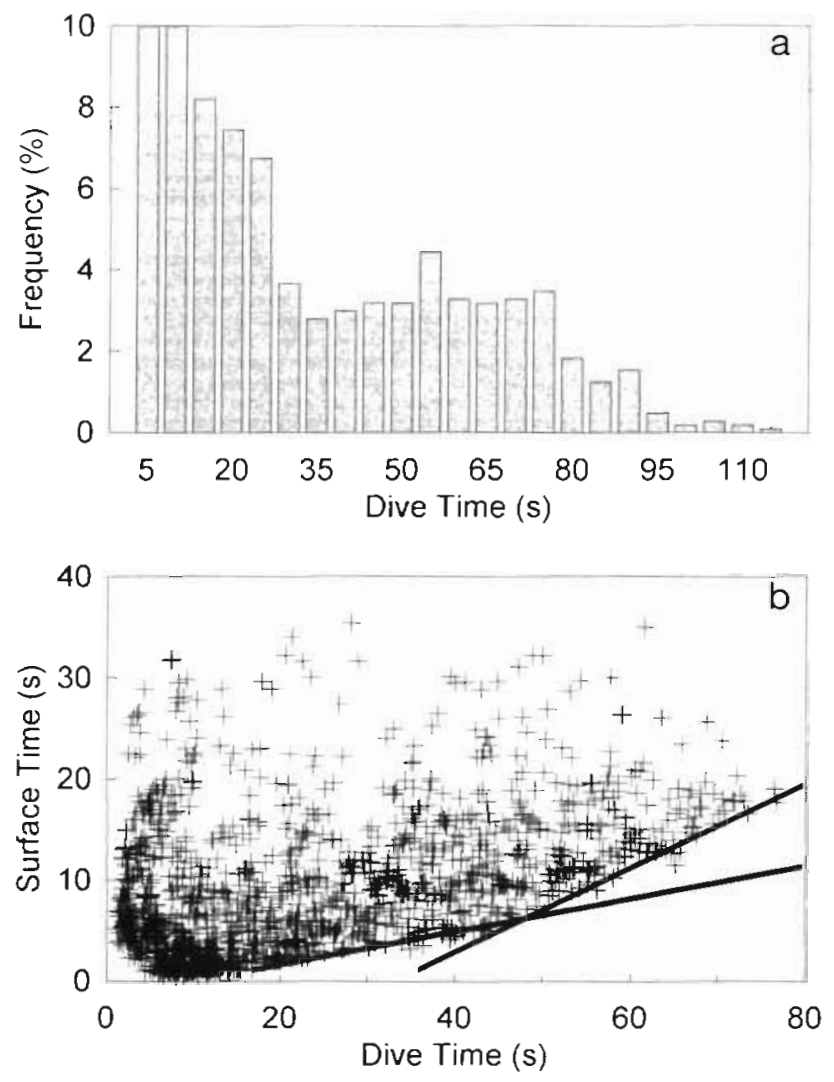

Fig. 4. Spheniscus humboldti. (a) Bimodal distribution of dive durations ( 5 and $55 \mathrm{~s}$ ) determined via VHF telemetry in 8 penguins ( $\mathrm{n}=1244$ ). (b) Dive vs surface times (from the running mean of 8 consecutive dives) showing minimum time at surface after a dive (black lines). Birds diving for $<50$ s need relatively less time at the surface than those diving for $>50 \mathrm{~s}$, as indicated by the difference in slopes

birds were presumably capturing prey (>35 s). We found mean durations of $8.4 \mathrm{~s}( \pm 9.2, \mathrm{n}=903)$ for travelling and $61.0 \mathrm{~s}( \pm 16.9, \mathrm{n}=341)$ for foraging dives. A plot (Fig. 4 b) of the running mean of 8 surface (ST, in s) versus dive ( $D T$, in s) times (running means of fewer dives did not yield a clear result, those of more dives showed the same pattern) showed that dives $>50 \mathrm{~s}$ were followed by relatively longer minimum surface times than dives shorter than $50 \mathrm{~s}$. The relationships shown are $S T_{\min }=0.16 D T-2.9$ for dives $<50 \mathrm{~s}$ and $S T_{\min }=0.45 D T-15.58$ for dives $>50 \mathrm{~s}$, where $S T_{\min }$ stands for minimum surface time after a dive.

\section{Area utilisation}

In order to find out how much Humboldt penguins deviate from a straight course during a foraging trip, we compared the actual distance swum by the birds (i.e. as observed on the surface via radio telemetry; this
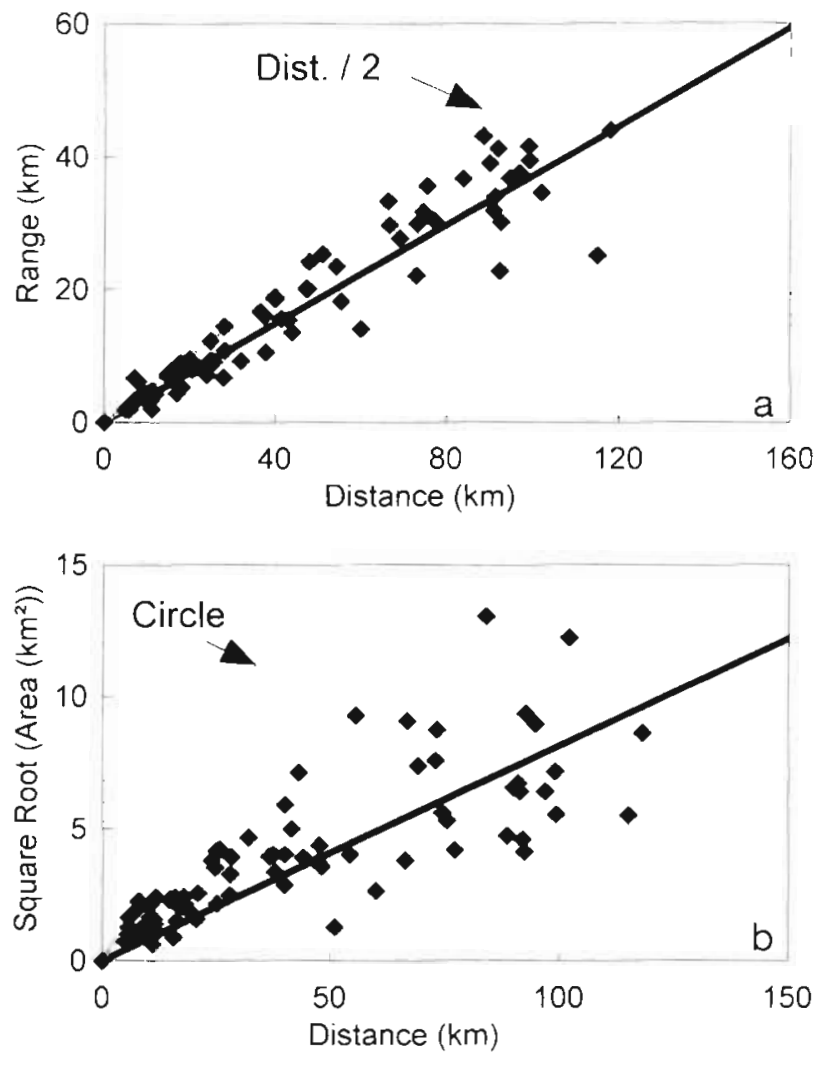

Fig. 5. Spheniscus humboldti. (a) Range $(R$, maximum distance from island) versus distance swum $(D)(\mathrm{n}=79)$. With a factor of 0.37 Humboldt penguins come close to the maximum of Range $=0.5 D$ (grey line). (b) Plot of square root of area covered vs foraging trip distance. Maximum possible values of square root area are shown for a circle (grey line)

does not include vertical distance) to their maximum range (Fig. 5a). We found that range $(R$, in $\mathrm{km})$ was related to distance $(D$, in $\mathrm{km})$ as $R=0.37( \pm 0.009) \times D$ $\left(\mathrm{r}^{2}=0.89, \mathrm{n}=79\right)$. The area $\left(A\right.$, in $\left.\mathrm{km}^{2}\right)$ covered by the birds (as delimited by the actual course of the penguins) during a foraging trip was related to distance swum by $A=6.631 \times 10^{-3}\left( \pm 1.3 \times 10^{-5}\right) \times D^{2}\left(\mathrm{r}^{2}=0.6\right.$, $\mathrm{n}=79$ ). The data are shown in Fig. $5 b$, as distance versus square root of area, to obtain a linear relationship.

\section{Synchrony of penguin activities}

Finally, we used our data to determine whether Humboldt penguins foraged synchronously, used specific feeding areas, and hunted cooperatively. Synchrony was analysed by determining the presence or absence of the birds from the island, and calculating the true percentage of birds at sea ('true' stands for birds whose transmitters could actually be received that day). While we were able to monitor all 8 penguins 

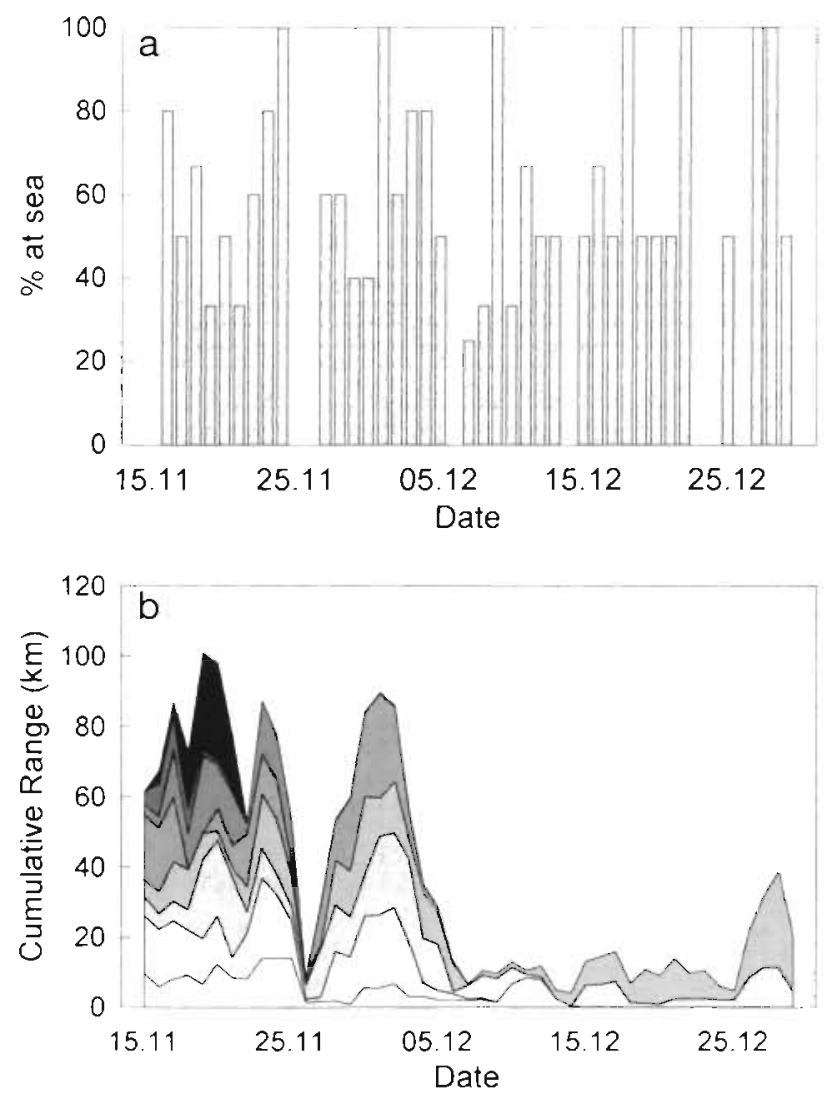

Fig. 6. Spheniscus humboldti. (a) Frequency distribution (\%) of transmitter-equipped Humboldt penguins at sea versus date. There is a very low degree of synchrony between burds. (b) Cumulative range (i.e. maximum distance of bird 1 from the island added to that of bird 2 etc., in $\mathrm{km}$ ) vs date. It appears that those birds foraging on the same day did so within similar ranges from the island

during some days (each bird acounting for $12.5 \%$ ), we could only follow up on 3 birds during other periods $(33 \%)$. The resulting graph (Fig. 6a) shows that the birds we equipped did not leave the island on the same days, or stayed on land in synchrony.

In order to obtain an overall picture of at-sea activities, we plotted the 3 d running mean (because foraging trips may last up to $3 \mathrm{~d}_{i}$ Culik \& Luna-Jorquera 1997) of the range from Pan de Azúcar Island versus date (Fig. 6b). The cumulative plot shows range of bird 1 added to range of bird 2 for the same date in order to highlight synchrony. As shown in Fig 6b. foraging ranges differ significantly between days (ANOVA, $\mathrm{n}=$ $164, p=0.02)$. Humboldt penguins foraging on November 17, 19 and 24 and on December 1, 17 and 27 ranged far from the island (maxima), while the same birds remained nearby on November 18, 22 and 26 and on December 7,14 and 18 (minima). The question arising from this was: would birds ranging far from the island choose similar feeding areas during these spe-
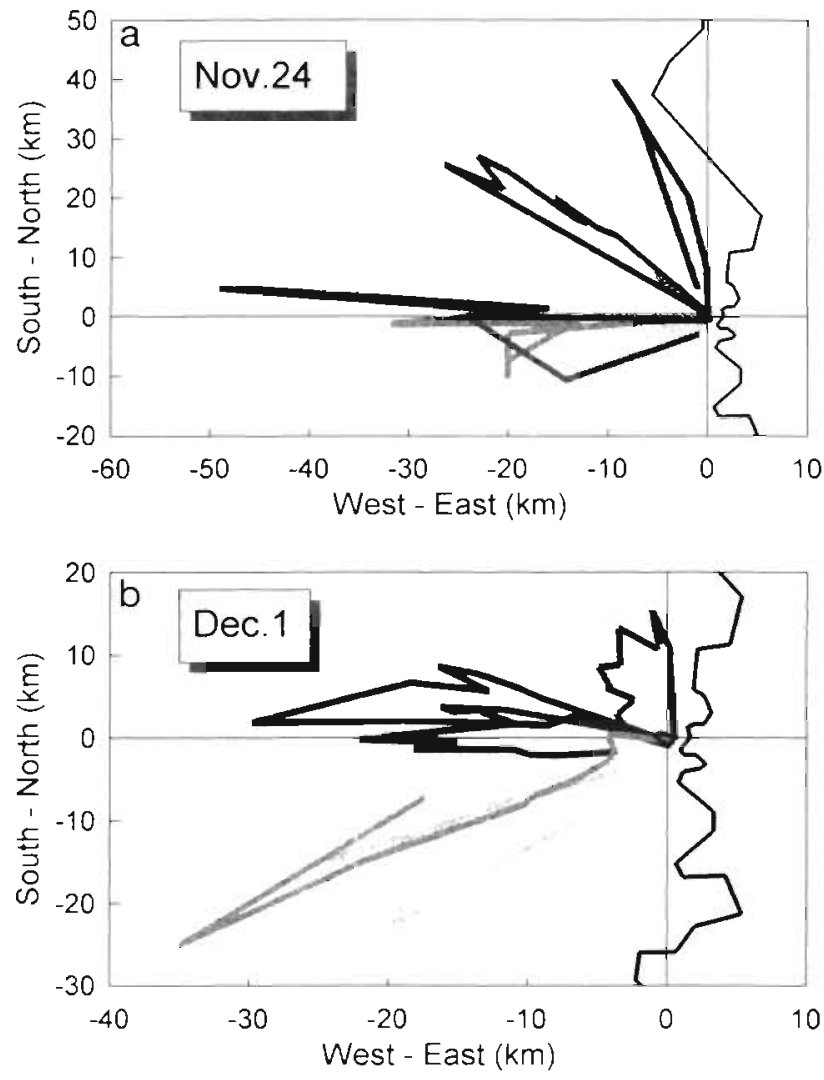

Fig. 7 Spheniscus humboldti. (a) Foraging tracks of 5 transmitter-equipped Humboldt penguıns from Pan de Azúcar on November 24. Four birds foraged $>25 \mathrm{~km}$ from the island. (b) Foraging tracks of 5 transmitter-equipped penguins on December 1. Four birds foraged $>20 \mathrm{~km}$ from the island. Note the difference in scales

cific days? In order to answer that question, we plotted the foraging tracks of all birds monitored on November 24 and December 1. on the same graphs, respectively (Fig. 7). The result shows that although the birds foraged far from their breeding island, their foraging tracks hardly overlapped.

\section{DISCUSSION}

\section{Foraging range}

In a previous study, Culik \& Luna-Jorquera (1997) used satellite transmitters (ST 10 PTT, Telonics) to determine where Humboldt penguins from Pan de Azúcar Island forage. They found that $90 \%$ of the locations were from an area with a radius of $35 \mathrm{~km}$ around the breeding island and suggested that this area be protected from fisheries in order to avoid competition for penguin food resources or entanglement of the 
birds in nets. The size of this area coincides well with the results presented here (Fig. 2), as $98 \%$ of all locations came from within this radius. The difference of $8 \%$ could be attributed to the fact that in transmitterequipped penguins, range was limited (maximum observed was $55 \mathrm{~km}$ ), which reduced the number of successful locations to a smaller area.

The distribution of Humboldt penguins around Pan de Azúcar Island also compares well to estimates from other spheniscid species. Using speed meters, Wilson et al. (1989) found that African penguins with small and medium sized chicks foraged within an average range of 11 and $15 \mathrm{~km}$ of their island, respectively. Heath \& Randall (1989) also studied African penguins at a different locality than Wilson et al. (1989) and found mean foraging ranges of $40 \mathrm{~km}$ for the 12 birds studied. Their birds, however, concentrated feeding efforts in a specific area. Wilson et al. (1988) counted African penguins at sea and found that, during the breeding season, $50 \%$ of the birds were seen within $3 \mathrm{~km}$ of the coast. The present study showed that $75 \%$ of all locations were obtained from within a $5 \mathrm{~km}$ radius of Pan de Azúcar Island.

Our estimate of distance swum during foraging trips $(44.5 \mathrm{~km})$ does not incorporate vertical distance associated with foraging dives as opposed to measurements obtained via speed meters. Bearing this in mind, however, the present estimate compares well to that of Luna-Jorquera \& Culik (1997) who found $60.3 \mathrm{~km}$ using speed loggers (at Pan de Azúcar Island). Birds from Pan de Azúcar seem to swim farther during the same period of the breeding season than their conspecifics from Chanaral $\left(29^{\circ} 01^{\prime} \mathrm{S}, 71^{\circ} 50^{\prime} \mathrm{W}\right)$ and Pajaro Niño $\left(33^{\circ} 39^{\prime} \mathrm{S}, 71^{\circ} 45^{\prime} \mathrm{W}\right)$ Islands. Wilson et al. (1989), using speed meters, found mean travelling distances of 32.2 and $50.6 \mathrm{~km}$, respectively, at these localities. However, these differences may also be attributable to local or temporal differences in food availability.

\section{Travelling speed}

The mean travelling speed of Humboldt penguins determined here $\left(0.92 \mathrm{~m} \mathrm{~s}^{-1}\right.$; Fig. 3) was almost identical to that measured via satellite telemetry $\left(0.94 \mathrm{~m} \mathrm{~s}^{-1}\right.$; Culik \& Luna-Jorquera 1997), although the temporal and spatial resolution (16 locations $\mathrm{d}^{-1}$ here, as opposed to a mean of 2.7 locations $\mathrm{d}^{-1}$ via satellite) was much greater. This shows that the filters used in both studies were appropriate. The distribution of travelling speeds determined via VHF telemetry also coincides very well with the results of the satellite telemetry study (Culik \& Luna-Jorquera 1997) and with the distribution of swimming speeds determined via dataloggers (Mk6, Wildlife Computers, Redmont, WA, USA) by Luna-Jorquera \& Culik (1997). In all cases, speed distribution showed 2 modes, one at 1.6 to $1.8 \mathrm{~m} \mathrm{~s}^{-1}$ and a second at $3 \mathrm{~m} \mathrm{~s}^{-1}$. The mode at 1.6 to $1.8 \mathrm{~m} \mathrm{~s}^{-1}$ agrees well with previously published mean swimming speeds of $1.9 \mathrm{~m} \mathrm{~s}^{-1}$ in Humboldt penguins (Wilson et al. 1995). Taking the precision of the different methods into account, this suggests that the drag effects of all instruments employed to date were comparable. Humboldt penguins are slow swimmers as opposed to other penguin species (Wilson 1995), and their preferred swimming speeds are probably only around 1.6 to $1.9 \mathrm{~m} \mathrm{~s}^{-1}$. However, the birds can also swim at high speeds (presumably porpoising) at $3 \mathrm{~m} \mathrm{~s}^{-1}$. The results presented here show that this is not uncommon, and that porpoising occurs $2.3 \%$ of the time.

\section{Comparison of methods}

From the results discussed so far, we conclude that satellite transmitters, data loggers and VHF transmitters employed on Humboldt penguins during the breeding season yielded complementary results, despite their differences in size, shape, mass or antenna length. The reason for this may lie in the fact that all the devices were streamlined according to the suggestions made in Bannasch et al. (1994), thereby inflicting a minimum of additional drag on the birds (cf. Culik et al. 1994). However, the 'psychological effect' of wearing a device, of being handled or of humans regularly visiting the area might have been responsible for the poor breeding success of the equipped birds. Although in a previous study (Luna-Jorquera et al. 1997) we attempted to minimise the effects of the experimental procedure on the birds, seemingly with good results, this aspect needs to be further addressed in future studies involving Humboldt penguins. Unfortunately, besides being one of the most endangered and least studied species, we find Humboldt penguins also to be the most nervous, anxious and unpredictable birds with respect to nest-site fidelity.

\section{Dive duration}

Luna-Jorquera \& Culik (1997) determined dive times of penguins from the same locality using data loggers and found that the distribution of dive durations during travelling and foraging showed modes at 10 and $50 \mathrm{~s}$, and an overall frequency minimum at $35 \mathrm{~s}$, which almost coincides with the distribution presented here (Fig. 4a). A more detailed comparison with LunaJorquera \& Culik's (1997) mean dive durations is difficult, however, because they used a different filter to separate travelling from foraging dives. 
Horning (1992) first introduced the method of summing a series of dives to compare dive and surface durations and to determine the behavioural aerobic dive limit (bADL) from a series of consecutive dives. Interestingly, the number of 8 dives he reported was also optimal here and coincides with that reported by Culik et al. (1996) for king penguins Aptenodytes patagonicus. In Humboldt penguins, it appears (Fig. $4 \mathrm{~b}$ ) that the bADL would be located at $50 \mathrm{~s}$ dive duration. This is surprising, as Luna-Jorquera (1997) determined from energetic calculations that the aerobic dive limit (exhaustion of oxygen stores) of the species is reached much later, at $115 \mathrm{~s}$ after the onset of a dive.

It could be postulated that the increase in minimum surface durations beyond dive times of $50 \mathrm{~s}$ reflects the dynamics of oxygen uptake via lungs, blood (haemoglobin) and muscle (myoglobin) and, in addition, the turnover of accumulated lactate, a factor which becomes increasingly important with prolonged dives. If prolonged surface times beyond dive durations of $50 \mathrm{~s}$ reflect physiological constraints, then the diving behaviour of Humboldt penguins should be governed by 2 extremes (Fig. 4 b): on the one hand prolonged dives, e.g. $80 \mathrm{~s}$, with $20 \mathrm{~s}$ minimal surface duration, entailing a dive to surface ratio of about $4 / 1$; or short dives, e.g. $20 \mathrm{~s}$, with only $2 \mathrm{~s}$ at the surface, entailing a dive to surface ratio of $10 / 1$. The birds' optimal choice may depend on prey distribution, mobility and depth.

However, surface times may also reflect prey handling and/or ingestion after successful dives, and this may be dependent on prey size. Guerra (1992) found that around Pan de Azúcar Island, the main prey of Humboldt penguins (cf. Wilson et al. 1995), the anchoveta Engraulis ringens, is found within the top $30 \mathrm{~m}$ of the water column. With maximum descent and ascent rates of $1.7 \mathrm{~m} \mathrm{~s}^{-1}$ (Luna-Jorquera 1997), Humboldt penguins can easily capture and presumably handle this small (ca $4 \mathrm{~cm}$ ) prey within a $50 \mathrm{~s}$ dive. However, Wilson et al. (1995) found that at Chañaral Island, Humboldt penguins took mostly garfish Scomberox spp., which ranged up to $27 \mathrm{~cm}$ in size. This might entail longer pursuit times under water, higher oxygen expenditure and/or increased handling times at the surface, all of which would increase surface durations. Depending on the energy content of the prey and its availability, Humboldt penguins may have to select small prey (allowing for frequent dives) or large prey (less frequent dives) to optimise their catch per unit effort.

\section{Area utilisation}

Our data indicate no clear preference of Pan de Azúcar birds for specific marine areas (e.g Figs. 1 \& 7), which confirms the results of Culik \& Luna-Jorquera (1997). Furthermore, Humboldt penguins do not show preferences for certain foraging strategies. If they swum in a straight line, in and out, then range should exactly be half the distance swum (Fig. 5a), which was observed in some of the cases studied. If the birds were maximising the area covered, however, then their course should be circular, and range should be distance $/ 3.14$, or $R=0.32 D$. The mean factor of 0.37 found here is closer to that corresponding to area maximisation. However, we also analysed the relationship between area covered and distance swum (Fig. 5b) and found that the mean factor of $A=6.6 \times 10^{-3} D^{2}$ falls very much short of the factor $A=3.14 \mathrm{r}^{2}$ (for a circle) which corresponds to $A=0.08 D^{2}$.

Our results indicate, therefore, that Humboldt penguins show a high degree of directionality during their foraging trips, without attempting to maximise the area covered by their foraging tracks. This may be associated with the fact that the probability of prey encounter is not constant around the breeding island, and that the birds can only survey a small radius around their track. Under these circumstances, straight-line navigation may simplify the birds' task. How Humboldt penguins determine where to search for food when leaving the island is, however, still a mystery

\section{Behavioural synchrony}

Although we equipped all 8 animals within the same southeast side of the island, their behaviour did not seem to be synchronised (Fig. 6a). Instead, some birds chose to forage while others remained near the nest site on the same day. However, when the birds left the island to forage, the range of their foraging trips (maximum straight line distance of furthest position recorded from the island) was correlated between animals (Fig 6b), although the feeding areas overlapped only marginally (Fig. 7). This finding makes studies aimed at comparing Humboldt penguin at-sea activities with oceanographic features or prey availability as monitored via echo sounders very difficult. Presumably, the unpredictable prey availability around Pan de Azúcar Island is reflected by the unrecognisable pattern of penguin activities at sea.

Ashmole (1963) postulated that seabirds depleted fish stocks in the vicinity of their breeding colonies. The existence of a fish-free 'Ashmole halo' could either be determined by assessing fish density or by analysing predator behaviour. In the case of a centralplace foraging bird, such as Humboldt penguins which regularly return to their island, the only possibility to increase the chance of prey encounter during times 
of low abundance is to increase the search radius (= range). The reason is that the surface searched increases with the square of the radius (r), while at the same time the number of birds within a given area decreases by $\mathrm{r}^{-2}$. From the behaviour of Humboldt penguins, it seems that the probability of encountering prey is similar for approximately equidistant rings around the island, but increasing with range, which would explain why e.g. on November 24 and December 1 the birds ranged as far as possible.

Acknowledgements. This work was made possible through grants by the Deutsche Forschungsgemeinschaft, Bonn, Germany, to B.C. (Cu 24/3 1-3), and by the Deutscher Akademischer Austauschdienst, Bonn, to G.L. The Corporación Nacional Forestal, Copiapó, IIla Region, Chile, issued the permit to work in Pan de Azúcar National Park. We are particularly grateful for the help offered by the rangers of Pan de Azúcar National Park: I. Paez, E. Castillo, S. Cornejo, Y. Sanchez and $\mathrm{R}$. Ortega who manned the antennas. The fishermen of Caleta Pan de Azúcar, 'Oreja de pato' and 'Chamelo' helped us to commute between the mainland and the island.

\section{LITERATURE CITED}

Ashmole NP (1963) The regulation of numbers of tropical oceanic birds. Ibis 103:458-473

Bannasch R, Wilson RP. Culik B (1994) Hydrodynamic aspects of design and attachment of a back-mounted device in penguins. J Exp Biol 194:83-97

CAMP (1996) Conservation assessment and management workshop workbook. Conservation Breeding Specialist Group, Apple Valley, MN

Culik B, Bannasch R, Wilson RP (1994) External devices on penguins: how important is shape? Mar Biol 118:353-357

Culik B, Luna-Jorquera G (1997) Satellite tracking of Humboldt penguins Spheniscus humboldti in Northern Chile. Mar Biol 128:547-556

Editorial responsibility: Otto Kinne (Editor),

Oldendorf/Luhe, Germany
Culik BM, Pütz $K$, Wilson RP, Allers D, Lage J, Bost CA, Le $\$ laho $Y$ (1996) Diving energetics in king penguins (Aptenodytes patagonicus). J Exp Biol 199:973-983

Guerra C (1992) Efectos de la nidificacion estival/invernal sobre parámetros seleccionados de la historia de vida del pingüino de Humboldt Spheniscus humboldti. Informe Proyecto FONDECYT 90-0599, Universidad Antofagasta

Heath RGM, Randall RM (1989) Foraging ranges and movements of jackass penguins (Spheniscus demersus) established through radio-telemetry. J Zool Lond 217. $367-379$

Horning M[ (1992) Die Onthogenese des Tauchverhaltens beim Galapagos Seebären Arctocephalus galapagoensis Dissertation, Universität Bielefeld

Luna-Jorquera G (1997) Balancing the energy budget for a warm-blooded bird in a hot desert and cold seas: the case of the Humboldt penguin. Dissertation, ChristianAlbrechts-Universität, Kiel

Luna-Jorquera G, Culik BM (1997) Diving behaviour of Humboldt penguins (Spheniscus humboldti) in Northern Chile. Mar Ornithol (in press)

Luna-Jorquera G, Culik BM, Aguilar-Pulido R (1997) Minimising stress while capturing Humboldt penguins. Mar Ornithol (in press)

Williams TD (1995) The penguins Spheniscidae. Oxford University Press, Oxford

Wilson RP (1995) Foraging ecology. In: Williams TD (ed) The penguins. Oxford University Press, Oxford, p 81-106

Wilson RP, Duffy DC, Wilson MP, Araya B (1995) Aspects of the ecology of species replacement in Humboldt and Magellanic penguins. Gerfaut 85:49-61

Wilson RP, Nagy KA, Obst BS (1989) Foraging ranges of penguins. Polar Rec 25:353-357

Wilson RP, Wilson MP (1989) Tape: a package attachment technique for penguins. Wildl Soc Bull 17:77-79

Wilson RP, Wilson MP, Duffy DC (1988) Contemporary and historical patterns of African penguin (Spheniscus demersus) distribution at sea. Estuar Coast Shelf Sci 26:447-458

Zimmermann JP, Powell RA (1995) Radiotelemetry error: location error method compared with error polygons and confidence ellipses. Can J Zool 73:1123-1133

Submitted: May 27, 1997; Accepted: November 3, 1997

proofs received from author(s): January 19, 1998 